\title{
Correlation between mandibular gland secretion and cuticular hydrocarbons in the stingless bee Melipona quadrifasciata
}

\author{
C. Cruz-Landim ${ }^{1}$, M.J. Ferreira-Caliman' ${ }^{2}$ L.F. Gracioli-Vitti ${ }^{1}$ \\ and R. Zucchi ${ }^{2}$ \\ ${ }^{1}$ Departamento de Biologia, Instituto de Biociências de Rio Claro, \\ Universidade Estadual Paulista "Julio de Mesquita Filho", Rio Claro, SP, Brasil \\ ${ }^{2}$ Departamento de Biologia, \\ Faculdade de Filosofia Ciências e Letras de Ribeirão Preto, \\ Universidade de São Paulo, Ribeirão Preto, SP, Brasil \\ Corresponding author: C. Cruz-Landim \\ E-mail: cclandim@rc.unesp.br
}

Genet. Mol. Res. 11 (2): 966-977 (2012)

Received March 10, 2011

Accepted August 1, 2011

Published April 19, 2012

DOI http://dx.doi.org/10.4238/2012.April.19.2

\begin{abstract}
We investigated whether Melipona quadrifasciata worker mandibular gland secretions contribute directly to their cuticular hydrocarbon profile. The mandibular gland secretion composition and cuticular surface compounds of newly emerged worker bees, nurse bees, and foragers were determined by gas chromatography and mass spectrometry and compared. Both the mandibular gland secretions and the cuticular surface compounds of all worker stages were found to be composed almost exclusively of hydrocarbons. Although the relative proportion of hydrocarbons from the cuticular surface and gland secretion was statistically different, there was a high similarity in the qualitative composition between these structures in all groups of bees.
\end{abstract}

Key words: Melipona quadrifasciata; Mandibular gland secretion; Task-related hydrocarbons; Gas chromatography and mass spectrometry; Solid phase micro-extraction 


\section{INTRODUCTION}

There are many compounds, primarily hydrocarbons, associated with the cuticle of insects, whose main function is to protect terrestrial species against desiccation (Wigglesworth, 1970; Lockey, 1988; Gibbs, 1998). In addition to a protective function, cuticular hydrocarbons provide important recognition clues for all insects, especially social insects, in which chemical communication is essential to maintain the integrity of the colony and protect against invaders. These chemical cues allow social insects to discriminate nest mates from invaders and constitute a type of individual fingerprint within the colony (Layton et al., 1994; Breed, 1998; Dani et al., 2001).

Aggressive behavior against invaders entering the colony is initiated by contact with specific parts of the alien body, suggesting that the cues to recognition come from the body surface (Hölldobler and Michener, 1980) where they function as contact pheromones (Ginzel et al., 2003; Howard and Blomquist, 2005; Buchwald and Breed, 2005; Provost et al., 2008). Reviews from Howard and Blomquist (2005) and Provost et al. (2008) have unequivocally demonstrated the importance of the cuticular compounds in the ecology and behavior of insects.

However, the sources of cuticular hydrocarbons still deserve better characterization. Part of the hydrocarbons are structural components of the epicuticle proper, which are responsible for the hydrophobic properties of the cuticle that protect against water loss, but other hydrocarbons are acquired from the environment. The comb wax and other materials stored in the colony are the source of the acquired cuticular hydrocarbons in social insects (Lockey, 1988; Breed et al., 1988; Arnold et al., 2000; Nunes et al., 2009a,b). Additionally, ingested food might also influence the composition of surface hydrocarbons (Liang and Silverman, 2000; Richard et al., 2004).

The structural compounds are synthesized in the oenocytes and passed through the epidermal cells to the cuticle (Kramer and Wingglesworth, 1950; Dielh, 1975). These components might be produced according a genetic program and may be the starting point to caste, sex and kin recognition. In adult holometabolous insects, the structural cuticular lipids are replaced and periodically restored. Although the oenocytes might be the primary source for the restoration of epicuticle hydrocarbons, several results point to an additional contribution from exocrine epidermal glands (Kullenberg et al., 1973; Bagnéres and Morgan, 1991; Oldham et al., 1994; Bergman and Bergström, 1997; Arnold et al., 2000; Dani et al., 1996, 2001).

Bees have nearly twenty different types of exocrine glands of epidermal origin, named according to the body appendices to which they are linked or to their location on the insect's body. Most of these glands produce pheromones (Cruz-Landim, 2008), of which some are hydrocarbons.

Morphological studies comparing the castes, sexes and life phases of the individuals of several eusocial species revealed glandular changes that corresponded to behavioral particularities, denoting great plasticity in their morphology and secretion composition (CruzLandim and Abdalla, 2002). In Melipona bicolor the morphology of the mandibular gland cells and the composition of their secretion changes according to caste, sex and the temporal activities of workers (Gracioli-Vitti et al., 2004; Gracioli-Vitti and Abdalla, 2006).

The aim of the present study was to answer two questions: i) do cuticular and gland secretion hydrocarbon profiles in the studied species vary among workers performing different tasks in the colony? ii) is there any correlation between the secretion of the mandibular glands and the composition of surface hydrocarbons? 


\section{MATERIAL AND METHODS}

Mandibular glands and wings were removed from eight workers from the same colony, from each of the following classes: newly emerged (E - workers leaving the brood cell), nurses $(\mathrm{N}$ - workers that provision the brood cells) and foragers ( $\mathrm{F}$ - workers that bring resources in from the field). The E workers were collected leaving the brood cell before taking any food or having any contact with the cerumen and other materials stored in the colony. The $\mathrm{N}$ bees were collected after provisioning the brood cells and the F were collected when they arrived back at the nest. Glands and wings were removed from the same individual and analyzed separately. The wings were chosen for the identification of the compounds present in the cuticle in order to avoid likely contamination from the products of nearby tegumentar glands. The mandibles were carefully dissected in distilled water under a stereo microscope, and the glands were separated for analysis.

\section{Hydrocarbons analysis}

The chemical composition of the samples was obtained by micro-extraction in solid phase using polydimethylsilosane fibers from SUPELCO (100 $\mu \mathrm{m}$ bounded) in direct contact with the samples (wings and glands). The fiber was gently rubbed for $10 \mathrm{~s}$ on the sample in order to absorb the chemical compounds. The fibers were then injected into a combined gas chromatography-mass spectrometer (GC-MS; SHIMADZU, model QP2010). Separation was achieved on a DB-5MS using a column of $30 \mathrm{~m}$ and a helium gas carrier at $1.0 \mathrm{~mL} / \mathrm{min}$. The oven temperature was initially set to $150^{\circ} \mathrm{C}$ and ramped up $3^{\circ} \mathrm{C} / \mathrm{min}$ until it reached $280^{\circ} \mathrm{C}$. The mass spectra was obtained by $70 \mathrm{eV}$ ionization, and the injections and analyses were performed in splitless mode.

The data were analyzed using GC-MS solutions for Windows (Shimadzu Corporation) and quantified by measuring the areas of the peaks in the chromatograms (Singer and Espelie, 1992). Chemical compounds were identified based on their mass spectra by comparison with Wiley Library data and with standard solutions of different synthetic hydrocarbons. Compounds present in less than three individuals in the same group and whose concentrations were below $0.5 \%$ were not included in the tables. Compounds present at concentrations below $0.5 \%$ and present in four or more individuals were represented in the tables as traces.

\section{Statistical analysis}

The compound profiles obtained for each body compartment (wings and mandibular glands) in workers of different life phases (newly emerged, nurse bee and forager) were compared using multivariate methods of principal component analysis and discriminant analysis that identified the specific hydrocarbons within the body compartments of each group and the discrimination among the groups (Davis, 1986; Krzanowiski, 2000, software XL Stat/version 2010).

\section{RESULTS}

The wing surface and mandibular gland secretion contained mostly hydrocarbons in all individuals tested. Farnesyl butanoate was found in addition to hydrocarbons at concentrations of 18 and $1.8 \%$, respectively (Table 1 ), only in nurse bees and foragers. 
Table 1. Average concentration of the compounds present in mandibular gland secretions and wing surfaces of newly emerged workers, nurse bees and foragers of Melipona quadrifasciata obtained for GC-ME.

\begin{tabular}{|c|c|c|c|c|c|c|c|}
\hline \multirow[t]{2}{*}{ RT (min) } & \multirow[t]{2}{*}{ Compounds } & \multicolumn{2}{|c|}{ Newly emerged } & \multicolumn{2}{|c|}{ Nurse } & \multicolumn{2}{|c|}{ Forager } \\
\hline & & Secretion & Wing & Secretion & Wing & Secretion & Wing \\
\hline 14.730 & Farnesyl butanoate & - & - & $18.01 \pm 15.51$ & - & $1.81 \pm 1.59$ & - \\
\hline 18.105 & Eicosane (C20) & $5.13 \pm 2.17$ & $6.35 \pm 2.22$ & - & - & - & - \\
\hline 22.808 & Tricosene & - & $0.95 \pm 0.39$ & $0.55 \pm 0.23$ & - & $0.70 \pm 0.23$ & $0.43 \pm 0.19$ \\
\hline 23.610 & Tricosane (C23) & $9.34 \pm 4.52$ & $14.00 \pm 4.97$ & $1.10 \pm 0.72$ & $1.97 \pm 1.05$ & $0.76 \pm 0.42$ & $2.10 \pm 1.30$ \\
\hline 25.510 & Tetracosene & - & $0.57 \pm 0.10$ & $1.10 \pm 1.06$ & $2.45 \pm 4.05$ & $1.03 \pm 0.35$ & $0.54 \pm 0.35$ \\
\hline 26.230 & Tetracosane (C24) & - & $8.29 \pm 17.99$ & $0.21 \pm 0.11$ & $0.65 \pm 0.40$ & $0.22 \pm 0.12$ & $0.46 \pm 0.23$ \\
\hline 27.977 & 1-Pentacosene & - & - & $0.63 \pm 0.47$ & $1.03 \pm 1.19$ & - & - \\
\hline 28.140 & 2-Pentacosene & $37.35 \pm 12.54$ & $27.14 \pm 11.54$ & $41.02 \pm 20.50$ & $31.97 \pm 23.65$ & $61.19 \pm 9.92$ & $49.55 \pm 10.19$ \\
\hline 28.377 & 3-Pentacosene & $5.48 \pm 4.19$ & $1.43 \pm 0.42$ & $4.72 \pm 9.81$ & $7.80 \pm 10.97$ & $3.89 \pm 4.8$ & $1.97 \pm 0.26$ \\
\hline 28.650 & 4-Pentacosene & - & - & $0.60 \pm 0.17$ & $0.45 \pm 0.28$ & $0.71 \pm 0.38$ & $1.12 \pm 1.21$ \\
\hline 28.860 & Pentacosane (C25) & $11.34 \pm 6.57$ & $16.39 \pm 13.33$ & $11.98 \pm 8.19$ & $22.45 \pm 15.15$ & $6.72 \pm 5.86$ & $14.26 \pm 6.59$ \\
\hline 29.600 & Methyl pentacosane & $3.70 \pm 2.15$ & $3.08 \pm 0.47$ & - & - & - & - \\
\hline 30.100 & Hexacosadiene & $2.02 \pm 1.01$ & $1.88 \pm 0.54$ & $0.53 \pm 0.24$ & $0.49 \pm 0.35$ & $0.24 \pm 0.04$ & $0.82 \pm 1.16$ \\
\hline 30.730 & Hexacosene & - & $0.81 \pm 0.11$ & $0.56 \pm 0.49$ & $0.49 \pm 0.15$ & $0.50 \pm 0.55$ & $0.32 \pm 0.07$ \\
\hline 31.380 & Hexacosane (C26) & Traces & Traces & $1.40 \pm 0.36$ & $0.94 \pm 0.53$ & $1.43 \pm 0.51$ & $1.17 \pm 0.32$ \\
\hline 32.779 & Heptacosadiene & - & - & $0.44 \pm 0.20$ & $0.71 \pm 0.29$ & - & - \\
\hline 33.180 & 1-Heptacosene & $19.97 \pm 5.00$ & $13.84 \pm 2.75$ & $15.99 \pm 3.24$ & $15.87 \pm 9.61$ & $19.45 \pm 3.85$ & $21.31 \pm 2.96$ \\
\hline 33.368 & 2-Heptacosene & - & $0.67 \pm 0.06$ & $0.98 \pm 1.36$ & $2.60 \pm 4.35$ & $0.62 \pm 0.19$ & $1.64 \pm 1.42$ \\
\hline 33.499 & 3-Heptacosene & - & - & $0.55 \pm 0.29$ & $0.35 \pm 0.29$ & $0.41 \pm 0.40$ & $1.65 \pm 2.54$ \\
\hline 33.874 & Heptacosane (C27) & $3.93 \pm 2.36$ & $5.11 \pm 6.53$ & $3.04 \pm 2.89$ & $15.71 \pm 25.38$ & $0.89 \pm 1.18$ & $2.57 \pm 1.62$ \\
\hline 34.603 & Methyl heptacosane & $4.64 \pm 5.56$ & $1.45 \pm 0.39$ & $0.46 \pm 0.32$ & $9.08 \pm 11.58$ & $0.21 \pm 0.12$ & $0.52 \pm 0.50$ \\
\hline 37.915 & Nonacosene & $6.13 \pm 3.56$ & $5.03 \pm 1.57$ & - & - & $0.44 \pm 0.20$ & $1.89 \pm 2.07$ \\
\hline 38.446 & Nonacosane (C29) & - & - & $0.84 \pm 0.49$ & $0.99 \pm 0.59$ & - & $0.36 \pm 0.18$ \\
\hline 39.140 & Methyl nonacosane & - & $0.81 \pm 0.29$ & $1.42 \pm 0.69$ & $2.15 \pm 2.37$ & - & - \\
\hline 40.300 & Triacontane & - & - & Traces & - & - & - \\
\hline 42.815 & Hentriacontane (C31) & - & - & - & Traces & - & - \\
\hline 44.900 & Dotriacontane (C32) & - & - & - & Traces & - & - \\
\hline
\end{tabular}

Data are reported as means $\pm \mathrm{SD}$ for $\mathrm{N}=8 . \mathrm{RT}=$ retention time. Traces $=$ compounds present at concentrations below $0.5 \%$ and present in four or more individuals.

The hydrocarbons identified included alkanes, alkenes, alkadienes, and branched hydrocarbons whose chain length varied from 20 to 32 carbon atoms (Table 1). A greater hydrocarbon diversity in mandibular gland secretion was found in $\mathrm{N}$ (22 compounds). In the wings, the variability was lower with 18 different compounds in the newly emerged and forager workers (Table 1; Figures 1, 2 and 3). Besides the variation in number, the concentration of hydrocarbons also varied, although 2-pentacosene was the most abundant hydrocarbon in both gland secretion and wing surface for all classes of workers. The concentration of this hydrocarbon increases from newly emerged workers to foragers and was always higher in gland secretions than in wings (Table 1).

Six new compounds appeared in the secretion of the nurse bees. All of them, except farnesyl butanoate, were also found in the wings and tricosene was not found in their wings (Table 1). A new compound, nonacosene, was found in the gland secretion of foragers, and was present in newly emerged workers, but not in nurse bees. The hydrocarbons 1-pentacosene, heptacosadiene and methyl nonacosene were not found in either the secretion or wing surface of N. Methyl nonacosene was present in the wings of $\mathrm{E}$.

The hydrocarbons present in the secretion and wing surface are almost the same (Table 1), except in newly emerged workers, where tricosene, tetracosene, tetracosane, hexacosene, 2-heptacosene, and methyl nonacosane are absent from the glandular secretion but present in the wings. In this class, there is less variation in the hydrocarbons expressed in the secretion and wing (12 and 18 different hydrocarbons, respectively) (Table 1). 


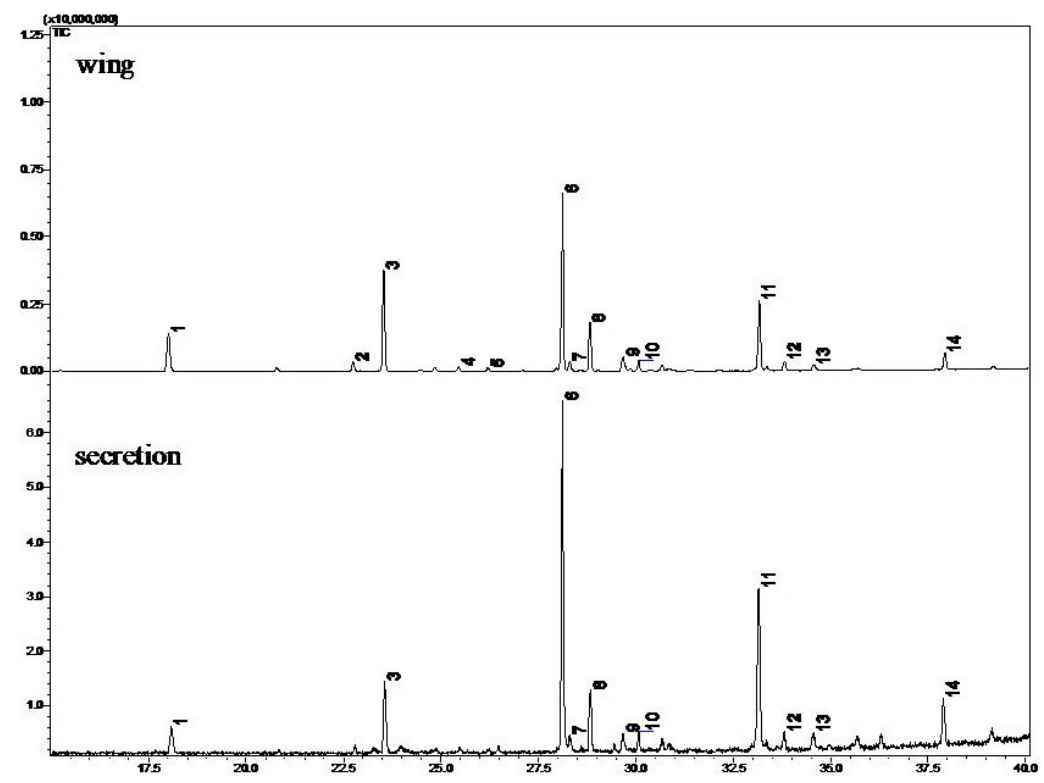

Figure 1. Gas chromatograms of newly emerged worker. Main peaks were: $1=$ eicosane; $2=$ tricosene; $3=$ tricosane; $4=$ tetracosene; $5=$ tetracosane; $6=2$-pentacosene; $7=3$-pentacosene; $8=$ pentacosane; $9=$ methyl pentacosane; $10=$ hexacosadiene; $11=1$-heptacosene; $12=$ heptacosane; $13=$ methyl heptacosane; $14=$ nonacosane.

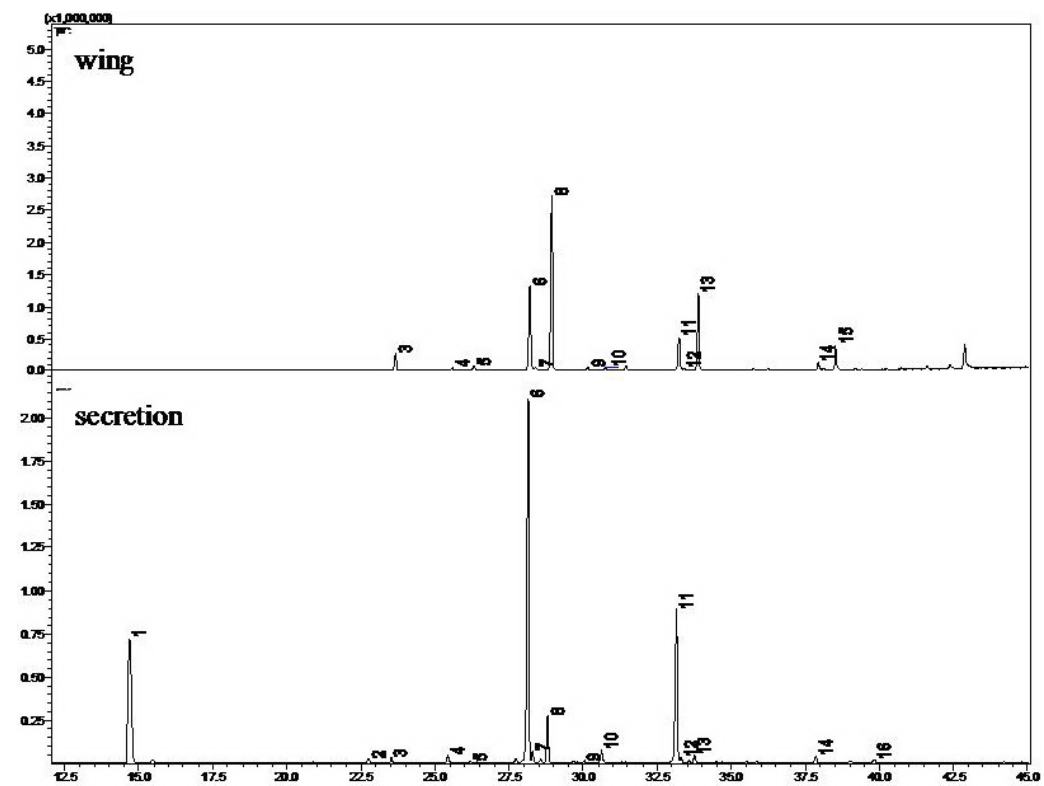

Figure 2. Gas chromatograms of nurse worker. Main peaks were: $1=$ farnesyl butanoate; $2=$ tricosene; $3=$ tricosane; $4=$ tetracosene; $5=$ tetracosane; $6=2$-pentacosene; $7=3$-pentacosene; $8=$ pentacosane; $9=$ hexacosadiene; $10=$ hexacosene; $11=1$-heptacosene; $12=2$-heptacosene; $13=$ heptacosane; $14=$ nonacosane; $15=$ methyl nonacosane; $16=$ triacontane. 


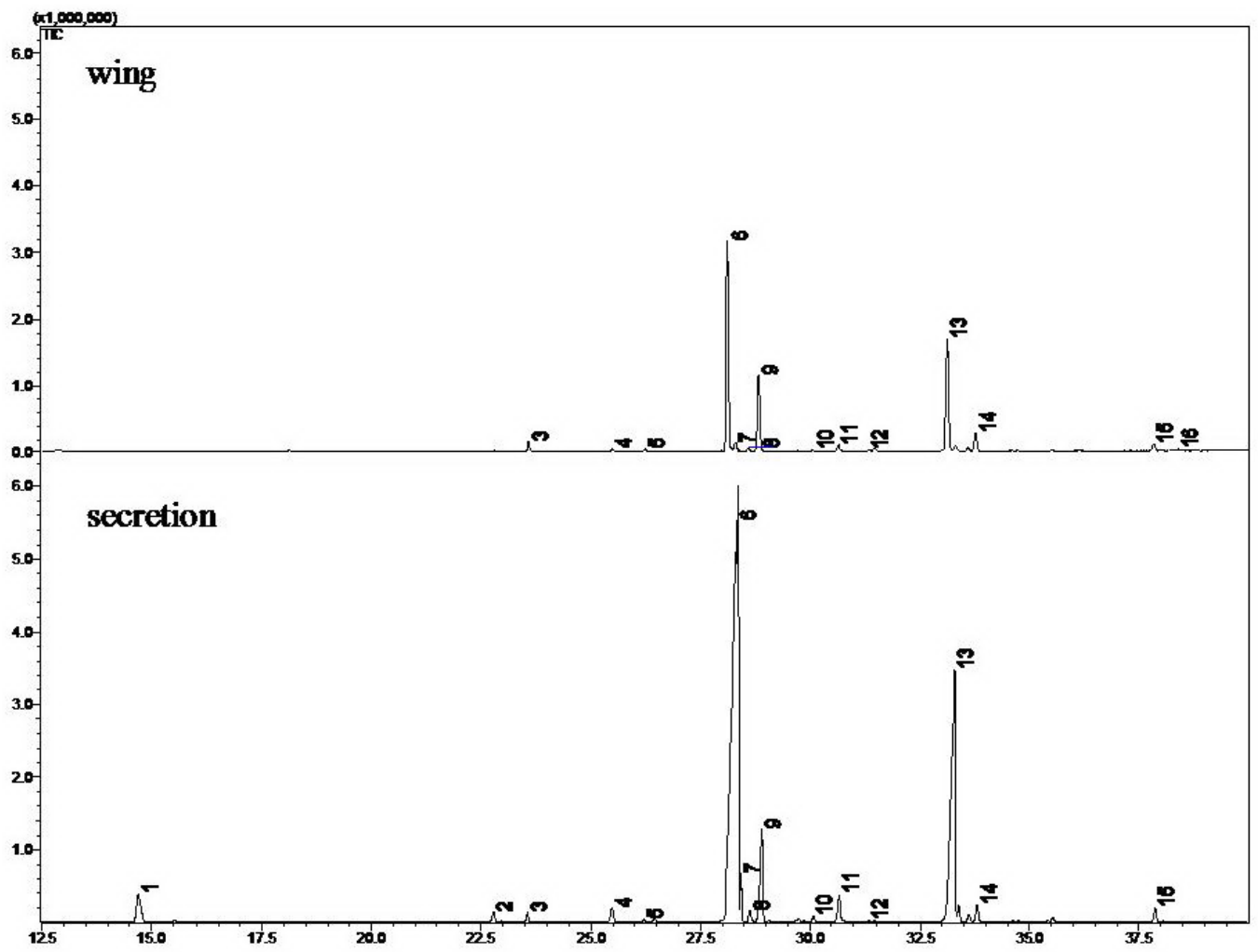

Figure 3. Gas chromatograms of forager worker. Main peaks were: $1=$ farnesyl butanoate; $2=$ tricosene; $3=$ tricosane; $4=$ tetracosene; $5=$ tetracosane; $6=2$-pentacosene; $7=3$-pentacosene; $8=4$-pentacosene; $9=$ pentacosane; $10=$ hexacosadiene; $11=$ hexacosene; $12=$ hexacosane; $13=1$-heptacosene; $14=$ heptacosane; $15=$ nonacosene; $16=$ nonacosane.

Despite the similarity in type of hydrocarbons present, the concentration of these compounds in secretion and wings of all classes of individuals is clearly different (Table 1; Figures 1, 2 and 3). Similar concentrations were found only for the hexacosadiene and 1-heptacosene in newly emerged and nurse bees, respectively (Table 1; Figures 1, 2 and 3).

A principal component analysis (Figure 4) shows which compounds contributed more significantly to the separation between the groups. Axis 1 accounts for $28.0 \%$ of the total variation, and axis 2 accounts for $24.41 \%$ of the total variation. Some relationships between the hydrocarbons within gland secretion and wing surface are indicated (e.g., heptacosane and 2-pentacosene with forager (SF in Figure 4) secretion and hexacosadiene and 3 -pentacosene with nurse wings (WN in Figure 4). Therefore, despite the $52.41 \%$ total variance, the scattered distribution suggests the existence of chemical compound clusters within secretion and wing surface (Figure 4).

The multigroup discriminating analysis revealed a statistical significance $(\alpha=$ 0.05 ) that separates all classes of workers as the compartments analyzed (mandibular gland secretions and wing surfaces), except for the glandular secretion and wing surface 
of nurse and forager bees, with $\mathrm{P}$ value $=0.292$ (Table 2; Figure 5). Therefore, as far as the hydrocarbon concentration is concerned, the composition of the wing/body surface is distinct from those of the mandibular gland secretion in all classes of workers and foragers (Figure 5; Table 2).

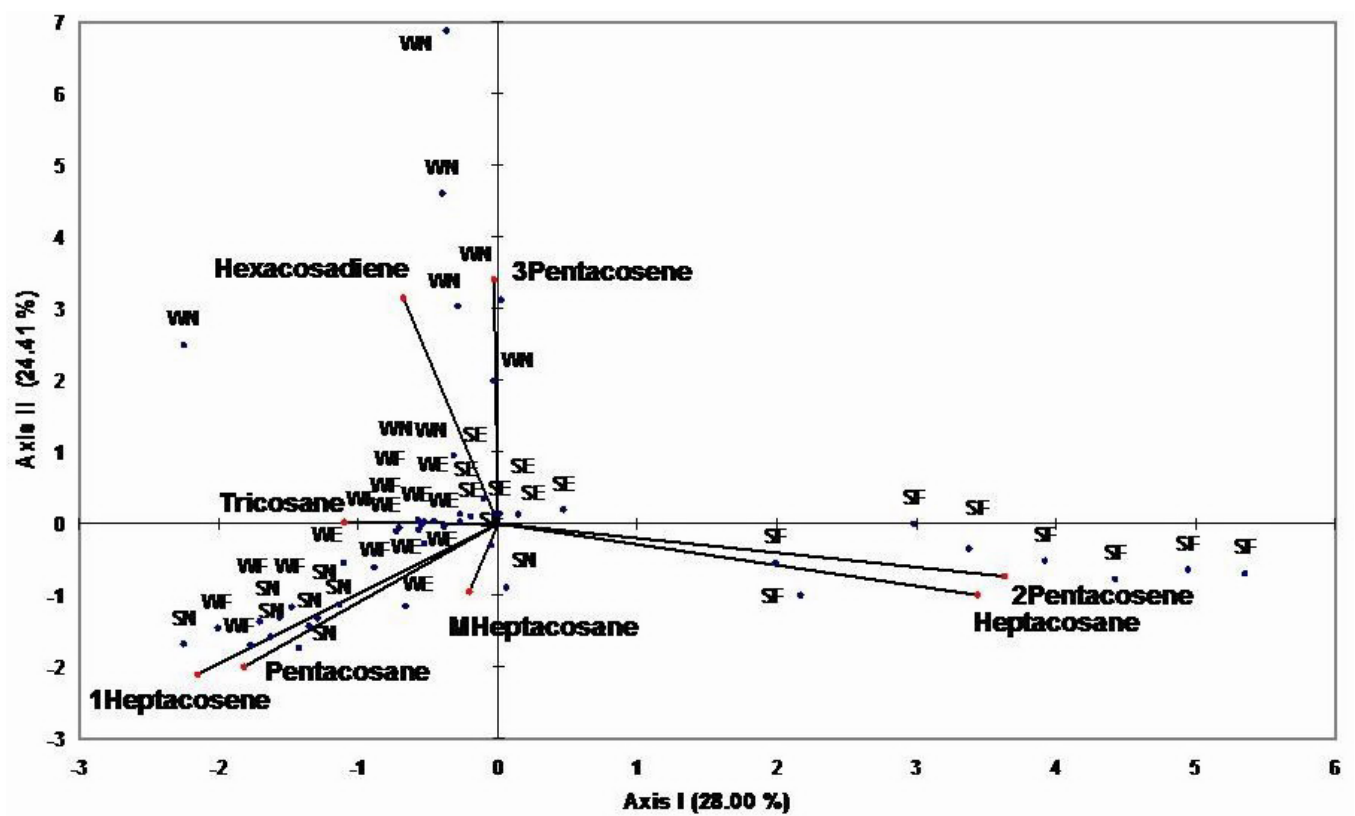

Figure 4. Principal component analysis biplot graphic showing the relationship between wing surface chemical compounds and mandibular gland secretions. $\mathrm{SF}=$ Mandibular gland secretions of foragers; $\mathrm{SE}=$ mandibular gland secretions of newly emerged workers; $\mathrm{SN}=$ mandibular gland secretions of nurse bees; WF = wing surfaces of foragers; $\mathrm{WE}=$ wing surfaces of newly emerged workers; $\mathrm{WN}=$ wing surfaces of nurse bees.

Table 2. P values for Fisher distances.

\begin{tabular}{lcccccc}
\hline & SF & SE & SN & WF & WE & WN \\
\hline SF & 1 & $<0.0001$ & $<0.0001$ & $<0.0001$ & $<0.0001$ & $<0.0001$ \\
SE & $<0.0001$ & 1 & $<0.0001$ & $<0.0001$ & $<0.0001$ & $<0.0001$ \\
SN & $<0.0001$ & $<0.0001$ & 1 & 0.292 & $<0.0001$ & $<0.0001$ \\
WF & $<0.0001$ & $<0.0001$ & 0.292 & 1 & $<0.0001$ & $<0.0001$ \\
WE & $<0.0001$ & $<0.0001$ & $<0.0001$ & $<0.0001$ & 1 & $<0.0001$ \\
WN & $<0.0001$ & $<0.0001$ & $<0.0001$ & $<0.0001$ & $<0.0001$ & 1 \\
\hline
\end{tabular}

$\mathrm{SF}=$ mandibular gland secretions of foragers; $\mathrm{SE}=$ mandibular gland secretions of newly emerged workers; $\mathrm{SN}=$ mandibular gland secretions of nurse bees; $\mathrm{WF}=$ wing surfaces of foragers; $\mathrm{WE}=$ wing surfaces of newly emerged workers; $\mathrm{WN}=$ wing surfaces of nurse bees.

The classification matrix of discriminant analysis indicates that a total of $87.50 \%$ of the analyzed individuals were correctly allocated in their predicted group (Table 3 ). 


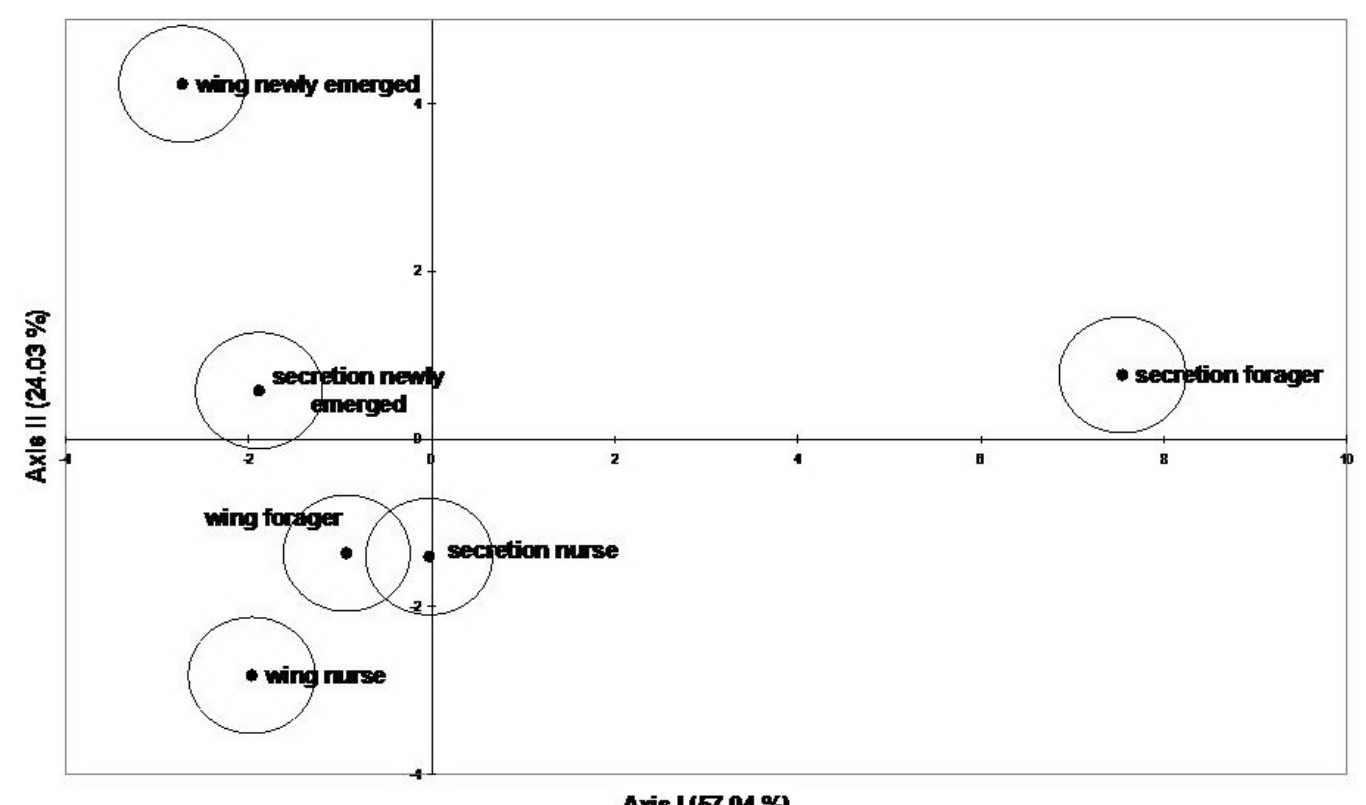

Axis 1 (57.04 \%)

Figure 5. Centroids of multigroup discriminant analysis for the chemical composition of the mandibular gland secretion and wing surface of Melipona quadrifasciata workers.

\section{Table 3. Classification matrix from discriminant analysis.}

\begin{tabular}{|c|c|c|c|c|c|c|c|c|}
\hline & SF & SE & SN & $\mathrm{WF}$ & WE & $\mathrm{WN}$ & Total & $\%$ Correct \\
\hline SF & 8 & 0 & 0 & 0 & 0 & 0 & 8 & 100.00 \\
\hline SE & 0 & 8 & 0 & 0 & 0 & 0 & 8 & 100.00 \\
\hline $\mathrm{SN}$ & 0 & 0 & 7 & 1 & 0 & 0 & 8 & 87.50 \\
\hline WF & 0 & 0 & 3 & 5 & 0 & 0 & 8 & 62.50 \\
\hline WE & 0 & 1 & 0 & 0 & 7 & 0 & 8 & 87.50 \\
\hline WN & 0 & 1 & 0 & 0 & 0 & 7 & 8 & 87.50 \\
\hline Total & 8 & 10 & 10 & 6 & 7 & 7 & 48 & 87.50 \\
\hline
\end{tabular}

$\overline{\mathrm{SF}}=$ mandibular gland secretions of foragers; $\mathrm{SE}=$ mandibular gland secretions of newly emerged workers; $\mathrm{SN}=$ mandibular gland secretions of nurse bees; WF $=$ wing surfaces of foragers; $\mathrm{WE}=$ wing surfaces of newly emerged workers; $\mathrm{WN}$ = wing surfaces of nurse bees.

\section{DISCUSSION}

The composition of the cuticular hydrocarbons and glandular secretions of bees has been primarily studied in an eco-functional context (Nunes et al., 2009a,b; Ferreira-Caliman et al, 2010) in which an examination of several colonies, sometimes from different locations, is necessary. In the present case, the aim was to compare the compositions of mandibular secretion and cuticular compounds within a single colony in order to search for similarities or discrepancies. To achieve this, a comparison of the chemical composition of wing and gland within the same bee was repeated in 8 different newly emerged, nurse and forager workers from the same colony. 
The statistical comparison among the worker classes and classification of wing $v s$ secretion takes into account the hydrocarbon types and concentrations in each compartment. Based on this analysis, the first question posed in the introduction can be partially answered in the negative when the percentage of hydrocarbons in both compartments studied is compared. Taking this parameter into account, it can be concluded that the profiles of both secretion and surface compounds allow the classes of workers displaying different tasks in the colony to be distinguished.

The composition of cuticular hydrocarbons is an important insight into intra- and interspecies communication in insects, especially in social insects, and it provides information about, sex, caste, fertility, task, co-specificity, and nest-mate conditions (Blomquist et al., 1998; Monnin and Peeters, 1999; Sledge et al., 2001; Greene and Gordon, 2003; Provost et al., 2008; Nunes et al., 2009a,b; Ferreira-Caliman et al, 2010). The present results suggest that in $M$. quadrifasciata, three categories of workers are recognizable based on their hydrocarbon profiles. Because the composition of the cuticular hydrocarbons is determined genetically (Dronnet et al., 2006; Foley et al., 2007) and the oenocyte is the main source of insect cell secreted hydrocarbons (Wigglesworth, 1970; Dielh, 1975; Billeter et al., 2009), this result warrants future investigation into the particularities of colony memberkinship in this species. Contradicting what was found in Apis mellifera by Breed et al. (1988), the foragers did not show greater variety of cuticular compounds than the other two classes of workers analyzed. According to these authors, the foragers contain a greater variety of cuticular compounds that assist in the recognition of nest mates. However, the results found by us are in agreement with other studies on stingless bees (Abdalla et al., 2003; Nunes et al., 2009b; Ferreira-Caliman et al., 2010).

However, hydrocarbons are also produced without oenocyte assembly (Fan et al., 2003), and several other sources have been hypothesized as an alternative origin of these compounds. For instance, similarities between the gland secretions from epidermal origin and cuticular hydrocarbons were found (Kullenberg et al., 1970; Oldham et al., 1994; Bergman and Bergström, 1997), and environmental contributions (Breed et al., 1988; Arnold et al., 2000) were also reported. Despite these findings, the origin of the hydrocarbons in cells without oenocyte assembly is still not completely understood, which leads to our second question: is there any correlation between the secretion of the mandibular glands and the composition of surface hydrocarbons?

The composition of the cuticular hydrocarbons changes with the sex, caste, age, and task allocation of the bee, as shown in the present results and in previous studies (Abdalla et al., 2003; Nunes et al., 2009a,b; Ferreira-Caliman et al., 2010). In response to the same conditions, changes occur in the morphology and secretion composition of the mandibular and other glands (Gracioli-Vitti et al., 2004; Abdalla et al., 2004; Gracioli-Vitti and Abdalla, 2006). When the results of gland secretion are statistically compared, the three classes of workers are quite different, and the statistical evidence shows a significant distinction between the cuticular and secretion composition of newly emerged and forager workers, but some similarity between both compositions in nurse bee workers.

Several cuticular hydrocarbons are contact pheromones, and some of the behaviors of recognition or aggression are released by individual contact, as is the case in queen recognition in A. mellifera. In addition, the mandibular gland secretion is frequently used for defense or attack (Kerr and Cruz, 1961; Hefetz et al., 1979; Smith and Roubik, 1983; Cruz-Lopez et al., 2005).

The above findings provide evidence that gland secretions might be spread on the body 
surface and become part of the cuticular hydrocarbons. The queen substance in A. mellifera is a classic example (Gary, 1962). Taking into account the previous findings, some correlations might be established between secretion and cuticular compounds. In spite of the statistical results, the contribution of the mandibular gland secretion to the cuticular compounds should not be disregarded. The results and the statistical treatment make it clear that differences among the individuals (wings and secretion) rely on the relative concentrations of compounds, and not on compound types. As they are, the present results show that there is a correlation between the composition of the mandibular gland secretion and the hydrocarbons, but not in the relative concentration within both compartments. Comparing results obtained from a different approach to the results presented here might reveal more biologically significant relationships because the hydrocarbons present in the three classes of individuals studied are very similar. An expected conclusion is that for individual recognition, what matters most is not the presence or absence of a given compound, but the final "bouquet", and that the statistical differences seem to be due in lesser part to the type of hydrocarbon present than to their concentrations.

\section{ACKNOWLEDGMENTS}

The authors thank Isabel Cristina Casanova Turatti for invaluable technical support in chemical analyses and FAPESP for financial support.

\section{REFERENCES}

Abdalla FC, Jones GR, Morgan ED and da Cruz-Landim C (2003). Comparative study of the cuticular hydrocarbon composition of Melipona bicolor Lepeletier, 1836 (Hymenoptera, Meliponini) workers and queens. Genet. Mol. Res. 2: 191-199.

Abdalla FC, Graeme RJ, Morgan D and Cruz-Landim C (2004). Chemical composition of the Dufour gland secretion in queens of Melipona bicolor (Hymenoptera, Meliponini). J. Braz. Chem. Soc. 15: 621-625.

Arnold G, Quenet B and Masson C (2000). Influence of social environment on genetically based subfamily signature in the honeybee. J. Chem. Ecol. 26: 2321-2333.

Bagnéres AG and Morgan ED (1991). The postpharyngeal gland and the cuticle of Formicidae contain the same characteristic hydrocarbons. Experientia 47: 106-111.

Bergman P and Bergström G (1997). Scent marking, scent origin, and species specificity in male premating behavior of two Scandinavian bumblebees. J. Chem. Ecol. 23: 1235-1251.

Billeter JC, Atallah J, Krupp JJ, Millar JG, et al. (2009). Specialized cells tag sexual and species identity in Drosophila melanogaster. Nature 461: 987-991.

Blomquist GJ, Tillman JA, Mpuru S and Seybold SJ (1998). The Cuticule and Cuticular Hydrocarbons of Insects: Structure, Function, and Biochemistry. In: Pheromone Communication in Social Insect (Vander Meer RK, Breed MD, Winston ML and Espelie KE, eds.). Westview Press, Boulder, 35-54.

Breed MD (1998). Chemical Cues in Kin-Recognition: Criteria for Identification, Experimental Approaches, and the Honey Bee as an Example. In: Pheromone Communication in Social Insects (Vander Meer RK, Breed MD, Espelie KE and Winston ML, eds.). Westview Press, Boulder, 57-78.

Breed MD, Williams KR and Fewell JH (1988). Comb wax mediates the acquisition of nest-mate recognition cues in honey bees. Proc. Natl. Acad. Sci. U. S. A. 85: 8766-8769.

Buchwald R and Breed M (2005). Nestmate recognition cues in stingless bee. Trigona fulviventris. Anim. Behav. 70: 1331-1337.

Cruz-Landim C (2008). Abelhas: Morfologia e Função de Sistemas. Editora Unesp, São Paulo.

Cruz-Landim C and Abdalla FC (2002). Glândulas Exócrinas das Abelhas. FUNPEC-RP, Ribeirão Preto.

Cruz-Lopez L, Malo EA, Morgan ED, Rincon M, et al. (2005). Mandibular gland secretion of Melipona beecheii: chemistry and behavior. J. Chem. Ecol. 31: 1621-1632.

Dani FR, Fratini S and Turillazzi S (1996). Behavioural evidence for the involvement of Dufour's gland secretion in nestmate recognition in the social wasp Polistes dominulus (Hymenoptera: Vespidae). Behav. Ecol. Sociobiol. 38: 311-319.

Dani FR, Jones GR, Destri S, Spencer SH, et al. (2001). Deciphering the recognition signature within the cuticular 
chemical profile of paper wasps. Anim. Behav. 62: 165-171.

Davis JC (1986). Statistic and Data Analysis in Geology. John Wiley and Sons, New York.

Dielh PA (1975). Synthesis and release of hydrocarbons by the oenocytes of the desert locust, Schistocerca gregaria. J. Insect Physiol. 21: 1237-1246.

Dronnet S, Lohou C, Christides JP and Bagneres AG (2006). Cuticular hydrocarbon composition reflects genetic relationship among colonies of the introduced termite Reticulitermes santonensis feytaud. J. Chem. Ecol. 32: 1027-1042.

Fan Y, Zurek L, Dykstra MJ and Schal C (2003). Hydrocarbon synthesis by enzymatically dissociated oenocytes of the abdominal integument of the german cockroach, Blattella germanic. Naturwissenschaften 90: 121-126.

Ferreira-Caliman MJ, Nascimento FS, Turatti IC, Mateus S, et al. (2010). The cuticular hydrocarbons profiles in the stingless bee Melipona marginata reflect task-related differences. J. Insect Physiol. 56: 800-804.

Foley B, Chenoweth SF, Nuzhdin SV and Blows MW (2007). Natural genetic variation in cuticular hydrocarbon expression in male and female Drosophila melanogaster. Genetics 175: 1465-1477.

Gary NE (1962). Chemical mating attractants in the queen honey bee. Science 136: 773-774.

Gibbs AG (1998). Water-proofing properties of cuticular lipids. Am. Zoologist 38: 471-482.

Ginzel MD, Blomquist GJ, Millar JG and Hanks LM (2003). Role of contact pheromones in mate recognition in Xylotrechus colonus. J. Chem. Ecol. 29: 533-545.

Gracioli-Vitti LF and Abdalla FC (2006). Comparative ultrastructure of the mandibular gland in Scaptotrigona postica (Hymenoptera, Apidae, Meliponini) workers and males. Braz. J. Morphol. Sci. 23: 415-424.

Gracioli-Vitti LF, Abdalla FC, Silva-de-Moraes RLM and Jones GR (2004). The chemical composition of the mandibular gland secretion of Melipona bicolor Lepeletier, 1836 (Hymenoptera, Apidae, Meliponini): A comparative study among castes and sexes. J. Braz. Chem. Soc. 15: 777-781.

Greene MJ and Gordon DM (2003). Social insects: cuticular hydrocarbons inform task decisions. Nature 423: 32.

Hefetz A, Batra SWT and Blum MS (1979). Chemistry of the mandibular gland secretion of the Indian bee Pithitis smaragdula. J. Chem. Ecol. 5: 753-758.

Howard RW and Blomquist GJ (2005). Ecological, behavioral, and biochemical aspects of insect hydrocarbons. Annu. Rev. Entomol. 50: 371-393.

Hölldobler B and Michener CD (1980). Mechanisms of Identification and Discrimination in Social Hymenoptera. In: Evolution of Social Behavior: Hypotheses and Empirical Tests (Markl H, ed.). Chemie Gmbh, Weinheim, 35-38.

Kerr WE and Cruz CC (1961). Funções diferentes tomadas pela glândula mandibular na evolução das abelhas em geral e em "Trigona (Oxytrigona) tataira" em especial. Rev. Bras. Biol. 21: 1-16.

Kramer S and Wigglesworth VB (1950). The outer layer of the cuticle in the coackroach Periplaneta americana and the function of the oenocytes. Quant. J. Microsc. Sci. 91: 63-72.

Krzanowiski WJ (2000). Principles of Multivariate Analysis: A User's Perspective. Oxford University Press, Oxford.

Kullenberg B, Bergstrom G and Stallberg-Stenhagen S (1970). Volatile components of the cephalic marking secretion of male bumble bees. Acta Chem. Scand. 24: 1481-1485.

Kullenberg B, Bergström G, Bringer B, Calberg B, et al. (1973). Observation of scent marking by Bombus Latr. and Psithyrus Lep. Males (Hym., Apidae) and localization of site of production of the secretion. Zoom 1: 23-30.

Layton JM, Camann MA and Espelie KE (1994). Cuticular lipid profiles of queens, workers, and males of social wasp Polistes metricus say are colony-specific. J. Chem. Ecol. 20: 2307-2321.

Liang D and Silverman J (2000). "You are what you eat": diet modifies cuticular hydrocarbons and nestmate recognition in the Argentine ant, Linepithema humile. Naturwissenschaften 87: 412-416.

Lockey KH (1988). Lipids of the insect cuticle: origin, composition and function. Comp. Biochem. Physiol. 89: 595-645.

Monnin T and Peeters C (1999). Dominance hierarchy and reproductive conflicts among subordinates in a monogynous queenless ant. Behav. Ecol. 10: 323-332.

Nunes TM, Nascimento FS, Turatti IC, Lopes NP, et al. (2009a). Nestmate recognition in a stingless bee: does the similarity of chemical cues determine guard acceptance? Anim. Behav. 75: 1165-1171.

Nunes TM, Turatti ICC, Mateus S, Nascimento FS, et al. (2009b). Cuticular hydrocarbons in the stingless bee Schwarziana quadripunctata (Hymenoptera, Apidae, Meliponini): differences between colonies, castes and age. Genet. Mol. Res. 8: 589-595.

Oldham NJ, Billen J and Morgan ED (1994). On the similarity of the Dufour gland secretion and the cuticular hydrocarbons of some bumblebees. Physiol. Entomol. 19: 115-123.

Provost E, Blight O, Tirard A and Renucci M (2008). Hydrocarbons and Insect's Social Physiology. In Insect Physiology: New Research (Maes RP, ed.). Novascience Publishers, New York, 19-72.

Richard FJ, Hefetz A, Christides JP and Errard C (2004). Food influence on colonial recognition and chemical signature between nestmates in the fungus-growing ant Acromyrmex subterraneus subterraneus. Chemoecology 14: 9-16.

Singer TL and Espelie KE (1992). Social wasps use nest paper hydrocarbons for nestmate recognition. Anim. Behav. 44: 63-68. Sledge MF, Dani FR, Cervo R, Dapporto L, et al. (2001). Recognition of social parasites as nest-mates: adoption of 
colony-specific host cuticular odours by the paper wasp parasite Polistes sulcifer. Proc. Biol. Sci. 268: 2253-2260. Smith BH and Roubik DW (1983). Mandibular glands of stingless bees (Hymenoptera: Apidae): Chemical analysis of their contents and biological function in two species of Melipona. J. Chem. Ecol. 9: 1465-1472.

Wigglesworth VB (1970). Structural lipids in the insect cuticle and the function of the oenocytes. Tissue Cell 2: 155-179. 